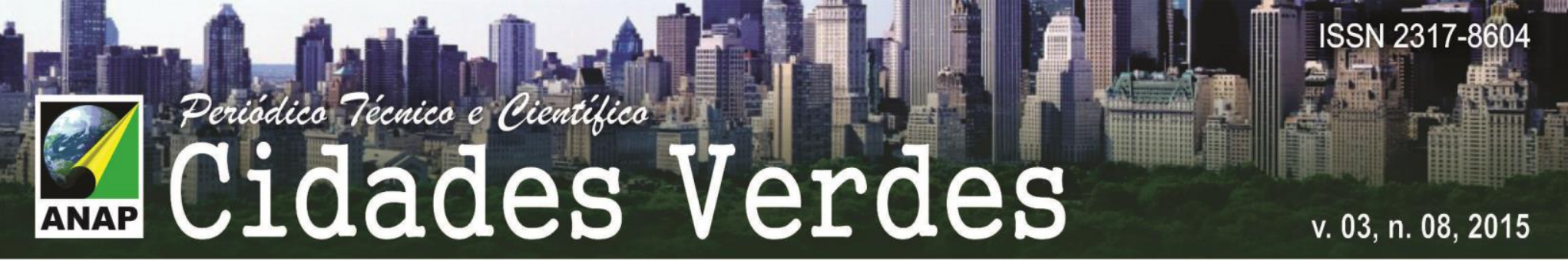

\title{
ESPAÇOS LIVRES PÚBLICOS EXISTENTES NA ÁREA URBANA CENTRAL DE GARANHUNS-PE
}

\author{
Amanda Cybelle Fernandes Cavalcant ${ }^{1}$
}

Maria do Carmo de Albuquerque Braga ${ }^{2}$

\begin{abstract}
RESUMO - Espaços livres são espaços abertos à população em geral, e alguns deles sob condições pré-estabelecidas pelo poder público como parques e praças. Classificam-se, em geral, como espaço público de equilíbrio ambiental e espaço público de recreação. Observa-se que nas grandes cidades, os lugares de encontro estão se limitando às áreas de comércio e shoppings, fazendo com que a ideia do lazer, do convívio social, antes desenvolvidas nas praças, não ocorra mais, com a mesma frequência. Nas cidades de médio porte como Garanhuns, a situação não é diferente, tendo esta experimentado, nas últimas décadas, uma razoável expansão urbana em função da chegada de centros de produção de conhecimento como universidades. Com isso, o objetivo deste trabalho foi de identificar e mapear os espaços livres públicos na área urbana central do município de Garanhuns e para tal, com o apoio teórico oferecido por Sá Carneiro \& Mesquita (2000), Leitão (2002) e Cunha (2002) entre outros como Dourado (2003), Almeida (2006) e Silva (2010), além do levantamento de campo, verificou-se que os espaços livres públicos de Garanhuns, em sua maioria, são do tipo praça. Localizam-se, em grande parte, no bairro de Santo Antônio, que é o bairro central do município e no bairro da Boa Vista. Apenas esses dois bairros somam um total de 9 praças, o que permite afirmar que tais espaços não se distribuírem de forma equilibrada em seu território, não cumprindo com uma das principais funções a que se destinam, que é a sociabilidade entre as pessoas do lugar.
\end{abstract}

PALAVRAS-CHAVES: Espaços livres. Recreação. Equilíbrio ambiental.

\section{FREE PUBLIC SPACES IN EXISTING URBAN AREA GARANHUNS-PE CENTRAL}

\begin{abstract}
Free spaces are spaces open to the general public, and some of them under preestablished by the government as parks and squares conditions. They are classified generally as public space for environmental balance and recreational public space. It is observed that in large cities, the meeting places are limited to shopping areas and malls, making the idea of leisure, social life, before developed in the streets, no longer occurs with the same frequency. In medium-sized cities as Garanhuns, the situation is no different, having experienced this in recent decades, a reasonable urban sprawl due to the arrival of knowledge production centers such as universities. Thus, the aim of

\footnotetext{
${ }^{1}$ Graduanda em Agronomia, Universidade Federal Rural de Pernambuco - Unidade Acadêmica de Garanhuns. E-mail: amanda_cybelles2@hotmail.com;

${ }^{2}$ Professora Adjunta da Universidade Federal Rural de Pernambuco - Unidade Acadêmica de

Garanhuns. E-mail: mariabraga77@gmail.com;
} 
this study was to identify and map the public open spaces in the central urban area of the municipality of Garanhuns and such with the theoretical support offered by Sá Carneiro \& Mosque (2000), Piglet (2002) and Cunha (2002) among others as Gold (2003), Almeida (2006) and Silva (2010), and the field survey, it was found that public open spaces Garanhuns, mostly, are the square type. , Is located largely in the San Antonio neighborhood, which is the central district of the city and in the district of Boa Vista. Only these two districts add up to a total of 9 squares, which allows us to state that such spaces do not distribute evenly in its territory is not complying with one of the main functions that are intended, which is sociability among the local people.

KEYWORDS: Free spaces. Recreation. Environmental balance.

\title{
ESPACIOS PÚBLICOS GRATUITOS EN ZONA URBANA
}

\section{ACTUAL GARANHUNS-PE CENTRAL}

\begin{abstract}
RESUMEN - Libre de espacios son espacios abiertos al público en general, y algunos de ellos menores de pre-establecido por el gobierno como parques y plazas condiciones. Se clasifican generalmente como espacio público para mantener el equilibrio del medio ambiente y el espacio público recreativo. Se observa que en las grandes ciudades, los lugares de reunión se limitan a las zonas comerciales y centros comerciales, por lo que la idea de ocio, la vida social, antes de que se desarrolló en las calles, ya no se produce con la misma frecuencia. En las ciudades medianas como Garanhuns, la situación no es diferente, habiendo experimentado esto en las últimas décadas, una expansión urbana razonable debido a la llegada de los centros de producción de conocimiento como las universidades. Por lo tanto, el objetivo de este estudio fue identificar y cartografiar los espacios públicos abiertos en la zona urbana central del municipio de Garanhuns y tal con el apoyo teórico ofrecido por Sá Carneiro y Mezquita (2000), Piglet (2002) y Cunha (2002 ), entre otros como Gold (2003), Almeida (2006) y Silva (2010), y el estudio de campo, se encontró que los espacios públicos abiertos Garanhuns, en su mayoría, son el tipo cuadrado. , Se encuentra en gran medida en el barrio de San Antonio, que es el distrito central de la ciudad y en el barrio de Boa Vista. Sólo estos dos distritos se suman a un total de 9 plazas, lo que nos permite afirmar que tales espacios no distribuyen uniformemente en su territorio no está cumpliendo con una de las principales funciones que se pretenden, que es la sociabilidad entre la gente local.
\end{abstract}

PALABRAS-CLAVE: Espacios libres. Recreación. El equilibrio del medio ambiente.

\section{INTRODUÇÃO}

Os espaços livres são espaços abertos à população em geral, e alguns deles sob condições pré-estabelecidas pelo poder público como parques, praças, entre outros (Sá Carneiro \& Mesquita, 2000). A autora subdivide o espaço livre em público e privado.

O espaço livre público é classificado como espaço público de equilíbrio ambiental e espaço público de recreação. Os de equilíbrio ambiental são espaços livres públicos com cobertura vegetal, podendo ter função de proteção de estruturas 
e infraestruturas. Estes são: unidades de conservação, cemitérios, campi universitários, espaços de valorização ambiental. Já os espaços públicos de recreação são espaços destinados ao desenvolvimento de atividades recreativas ou lúdicas, podendo ser faixa de praia, parques, praças, pátios, largos, jardins e quadras polivalentes. Estes espaços que constituem as cidades formam a paisagem e a cultura local.

Cunha (2002), ao realizar um trabalho sobre os espaços livres públicos e privados em Florianópolis-SC, coloca que são "elementos da paisagem urbana e devem ser definidos e diferenciados quanto às funções e tipos em projetos e análises espaciais que envolvem a cidade".

Outros autores como Leitão (2002), Dourado (2003) e Almeida (2006) também realizaram trabalhos nesse tema, tendo a primeira autora trabalho conceitos diferentes na filosofia, sociologia e urbanismo, a segunda, especificamente sobre espaços livres públicos em Lajedo-PE, e a terceira, em sua dissertação de mestrado, abordou os espaços públicos em João Pessoa entre 1889-1940, em suas formas, usos e nomes. Leitão (2002, p. 17), define espaço público somo sendo "o espaço onde as relações íntimas do grupo primário se enfraquecem e se fortalecem as relações coletivas que possibilitam as trocas fundamentais, o comércio com a diferença, marca da civilização".

O apoio do poder público local na construção e manutenção da cultura, do bem estar, do lazer e do convívio entre as pessoas é de fundamental importância. Observa-se que nas grandes cidades, os lugares de encontro entre as pessoas estão se limitando às grandes áreas de comércio e shoppings, fazendo com que a ideia do lazer, do convívio social, antes nas praças e campos de bairros, hoje sejam apenas lembranças.

Nas cidades de médio porte, a situação não é diferente. A expansão urbana causada pelo incentivo ao desenvolvimento por meio da implantação de grandes empreendimentos industriais, comerciais e de serviços, inclusive implantação de centros de produção de conhecimento como universidades, tem incentivado uma maior busca pela casa própria, pela atração de novos serviços, comércio, etc., passando despercebida a importância dos espaços livres públicos nesse contexto. 
Garanhuns, não difere desse contexto. Distando $230 \mathrm{Km}$ da capital do estado, Recife, e situando-se na região do agreste meridional de Pernambuco, o município como polo regional, apresenta um número populacional de 129.392 habitantes dos quais $48,10 \%$ sobrevive com uma renda domiciliar per capita abaixo de 1/2 salário mínimo (BDE/PE, 2011).

O município vem experimentando nas últimas décadas uma razoável expansão urbana em função da chegada de centros de produção de conhecimento como universidades federal, estadual e municipal, centros tecnológicos federal, estadual e municipal, além de um comércio diversificado. Suas características principais se concentram no clima diferenciado e na apresentação do verde em sua paisagem natural, ressaltando a diversidade em seu território, o que tem the propiciado denominações como "Cidade das Flores", "Suíça Pernambucana", entre outras.

\section{OBJETIVOS}

\section{Geral}

Identificar, classificar e mapear os espaços livres públicos existentes na área urbana do município de Garanhuns, de forma a ajudar o poder local a destinar e melhor definir usos desses espaços, de acordo com as necessidades básicas da população.

\section{Específicos}

- Pesquisar e estudar os conceitos, tipologias e características principais dos espaços livres públicos;

- Realizar levantamento na área urbana do município de Garanhuns, identificando a existência de diferentes tipos de espaços livres públicos;

- Realizar mapeamento dos espaços livres públicos existentes em Garanhuns, verificando sua distribuição na área urbana central do município; 


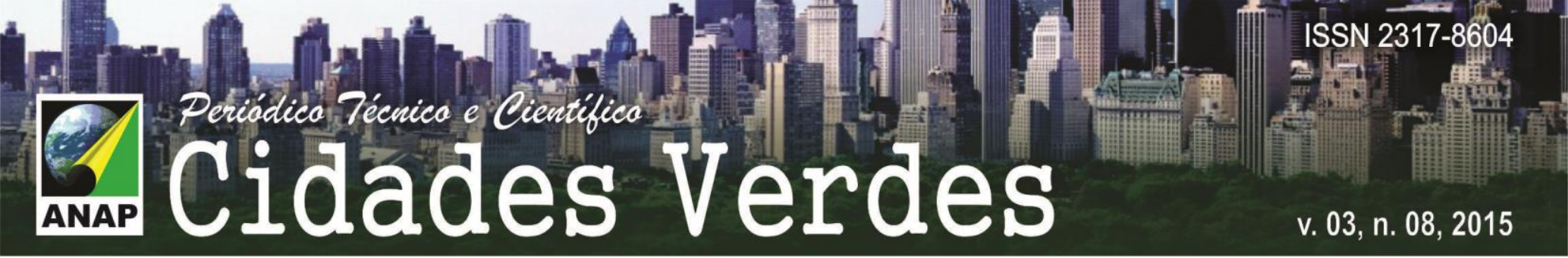

\section{METODOLOGIA}

Para realizar a identificação dos espaços livres públicos existentes na área urbana do município de Garanhuns, e ajudar ao poder local a destinar e melhor definir usos de acordo com as necessidades básicas da população, foi necessário realizar visitas aos órgãos públicos, pesquisas e estudos dos conceitos, tipologias e características principais desses espaços, para proceder a identificação e o levantamento dos mesmos, na área urbana de Garanhuns.

Diante disto, foi inicialmente definida qual seria a área urbana central do município, quando se verificou que esta não seria composta apenas pelo bairro de Santo Antônio, mas também por outros que apresentam sensível desenvolvimento e comércio diversificado. Assim, a área urbana central foi delimitada por bairros inteiros e por parte de outros (Figura1). O bairro que abrange sua totalidade é o de Santo Antônio, os outros são: São José, Magano, Aluísio Pinto, Heliópolis, Boa vista e Francisco Figueira. Para essa delimitação, tomou-se como referência as BR-423 e BR-424 que contornavam os bairros, com exceção do Francisco Figueira e do bairro Heliópolis.

Figura 1: Delimitação da área central de Garanhuns.

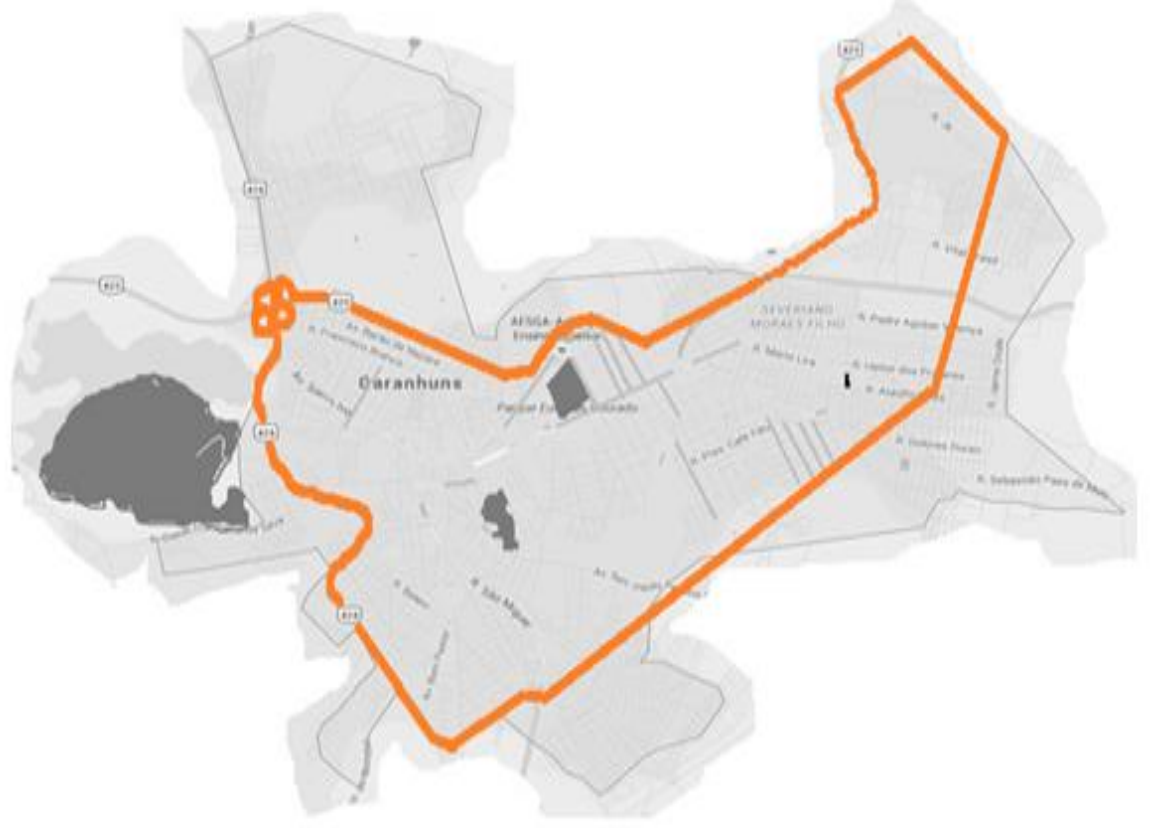

Fonte: AUTORAS, 2015. 
Após essa delimitação de área foi realizada a revisão de literatura, considerou principalmente Sá Carneiro \& Mesquita(2000), onde foi possível definir o que são espaços livres públicos e quais são estes espaços e não foi levado em consideração os espaços privados e livres de circulação.

\section{Topologia utilizada}

\section{ESPAÇOS LIVRES PÚBLICOS DE EQUILÍBRIO AMBIENTAIS}

\begin{abstract}
São vegetados e cumprem a função de elevar a qualidade ambiental e visual das cidades, ajudando a melhorar as condições higiênicas e de saúde pública e apoiar o descanso e a recreação de seus moradores. Podendo ser: Unidades de conservação, cemitérios, campi universitários, espaços de valorização ambiental.
\end{abstract}

Unidades de conservação - são porções do território nacional, de domínio público ou privado, incluindo áreas territoriais com características naturais de relevante valor ambiental, cultural paisagístico - mata, corpos d'agua, mangue, restinga - sob regimes especiais de administração e controlo. Esse conjunto deve ser tratado de forma a estabelecer a continuidade com os demais conjuntos residuais do antigo ecossistema através de corredores de proteção de vias rápidas, de estabilização biológica de taludes e proteção de linhas d'agua.

Cemitérios - são espaços livres públicos ou privados geralmente arborizados com destinação tradicional para repouso dos que morrem, podendo converter-se em locais aprazíveis ao silencio e a reflexão graças a presença de arborização adequada, inclusive, favorável a sobrevivência da avifauna urbana.

Campi universitários - são espaços livre públicos vegetados e contendo edificações de caratês educativo, incluindo mobiliário recreativo e áreas de contemplação.

Espaços de valorização ambiental - são espaços livres originados de um imóvel que contém uma parcela de vegetação concentrada e representativa por ser equivalente a superfície aproximada de um parque público da cidade, com área equivalente ou superior a uma quadra, e correspondente a $50 \%$ da área do terreno (SÁ CARNEIRO \& MESQUITA, 2000, p. 26-28).

\section{ESPAÇOS LIVRES PÚBLICOS DE RECREAÇÃO}

Segundo Silva (2010), são definidos como os que acontecem as atividades recreativas as quais são condicionantes para promover a integração social entre os grupos. Podendo ser: Faixa de praia, parques, praças, pátios, largos, jardins e quadra polivalentes. 
Faixa de praia - é o espaço livre com influência metropolitana que se desenvolve na área litorânea, com vegetação predominante de coqueiro, podendo conter como equipamentos de esportes - quadras, campos de futebol, equipamentos de ginástica, pista de skate, pista de Cooper, pista de patins - quanto de lazer contemplativo - bancos quiosques pergolados, etc. Parques - são espaços livres públicos com função predominante de recreação, ocupando na malha urbana uma área em grande equivalência superior a quadra típica urbana, em geral apresentando componentes da paisagem natural - vegetação, topografia, elemento aquático - como também edificações, destinadas a atividades recreativas, culturais e ou administrativas.

Praças - são espaços livres públicos com função de convívio social, inseridos na malha urbana como elemento organizador da circulação e de amenização pública, com área equivalente a uma quadra, geralmente contendo expressiva cobertura vegetal, mobiliário lúdico, canteiros e bancos.

Pátios - são espaços livres públicos definidos a partir de uma igreja ou outro elemento arquitetônico expressivo, além do casario antigos aos quais dá acesso, quase sempre pavimentados e exercendo a função de respiradouro, propiciadores do encontro social e eventualmente.

Largos - são os espaços livres públicos definidos a partir de um equipamento geralmente comercial, com fim de valorizar ou complementar alguma edificação como mercado público, podendo também ser destinado a atividades lúdicas temporárias.

Jardins - são os espaços livres públicos de contemplação que geralmente se estende ao longo de rios e canais, contendo cobertura vegetal representativa seja arbórea, arbustiva ou herbácea ou arranjo destes, com a finalidade de melhoria climática, ambiental e de valorização da paisagem.

Quadras polivalentes - são espaços livres destinados a pratica de jogos, bastante utilizados pela população, geralmente nos bairros populares, com revestimento de piso e quase sempre dispondo de área circundante, propicia para o encontro e o estar (SÁ CARNEIRO \& MESQUITA, 2000, p. $28-29)$.

Após a definição topológica foi realizada a visita de campo, para identificação destes espaços e realização do mapeamento (Figura 2). 


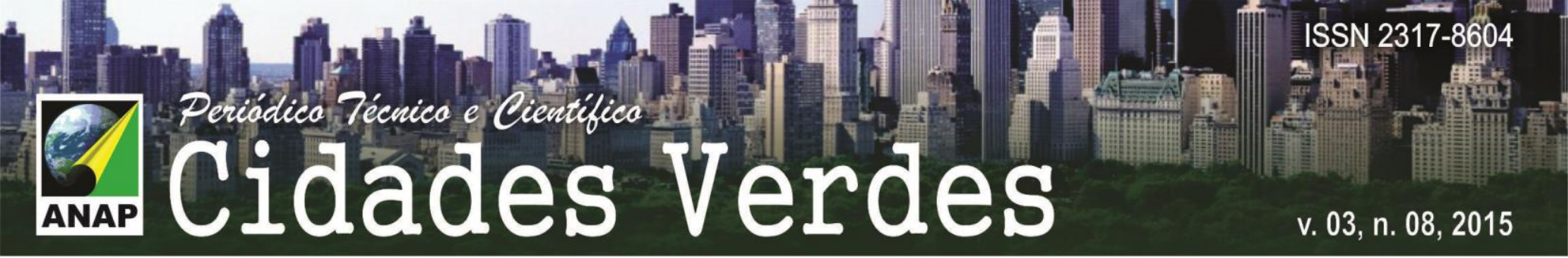

Figura 2: Mapeamento dos Espaços Livres Públicos de Garanhuns.

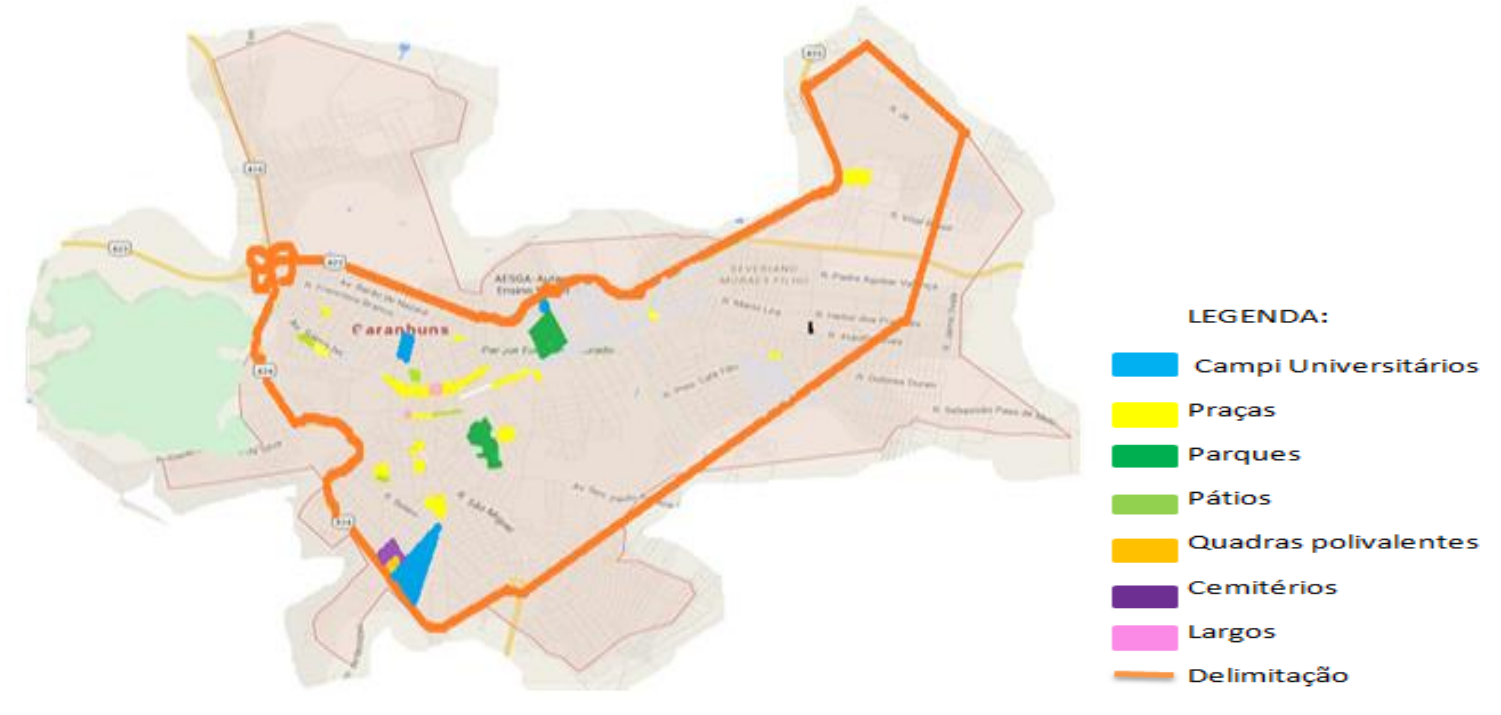

Fonte: AUTORAS, 2015.

\section{RESULTADO}

Ao utilizar a tipologia descrita por Sá Carneiro \& Mesquita(2000), foram identificados espaços livres públicos de equilíbrio ambiental, e espaços públicos de recreação, além de suas destinações e usos.

\section{- ESPAÇOS LIVRES PÚBLICOS DE EQUILÍBRIO AMBIENTAL}

Os espaços livres públicos de equilíbrio ambiental encontrados na cidade foram os cemitérios, campi universitários totalizando 4 , sendo 1 cemitério e 3 campi universitários (Tabela 1).

Tabela 1: Espaços livres públicos de equilíbrio ambiental em Garanhuns, PE.

\section{ESPAÇOS LIVRES PÚBLICOS DE EQUILIBRIO AMBIENTAL}

QUANTIDADE

Unidades de conservação

Cemitérios

Campi universitários

1

Espaços de valorização ambiental

TOTAL

4

Fonte: AUTORAS, 2015. 


\section{(1)

\section{- ESPAÇOS LIVRES PÚBLICOS DE RECREAÇÃo}

Com um total de 22 espaços livres públicos de recreação, apenas 13 são praças, os outros 9 estão distribuídos entre parques, pátios, largos e quadra polivalentes (tabela 2).

Tabela 2: Espaços livres públicos de recreação em Garanhuns, PE.

\section{ESPAÇOS LIVRES PÚBLICOS DE \\ RECREAÇÃO \\ QUANTIDADE}

Faixa de praia

Parques

Praças

Pátios

Largos

Jardins

Quadras Polivalentes

TOTAL

Fonte: AUTORAS, 2015.

\section{Parques}

Foram identificados dois parques o Euclides Dourado (figura 5), que se localiza no bairro de Heliópolis e o parque Ruben Van der Linder, que se localiza no bairro de Santo Antônio. O primeiro, além de oferecer área verde, dispõe de pista de cooper, academia das cidades, parque infantil, área de esportes, biblioteca e área de contemplação. O segundo parque, popularmente conhecido por Pau-pombo, possui além da área verde, pequeno parque infantil e uma sementeira. Ambos os parques ainda podem ser considerados como largos, pois recebem atividades lúdicas, 


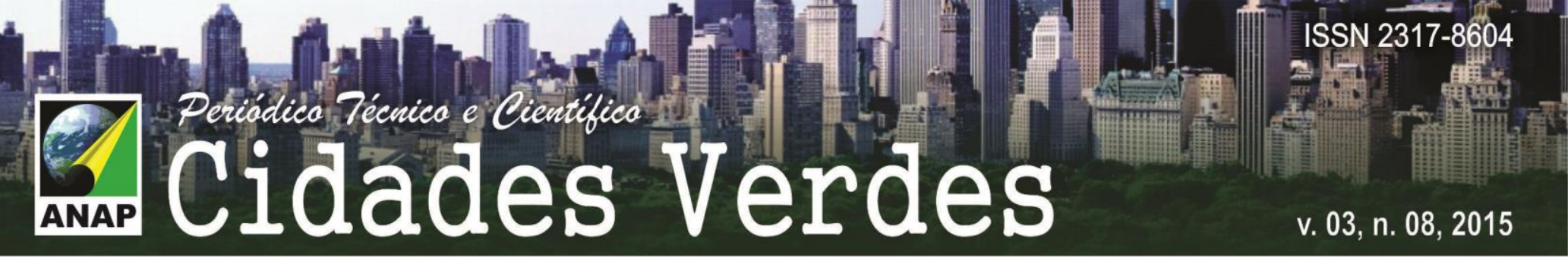

principalmente durante o mês de julho onde ocorre o famoso Festival de Inverno de Garanhuns.

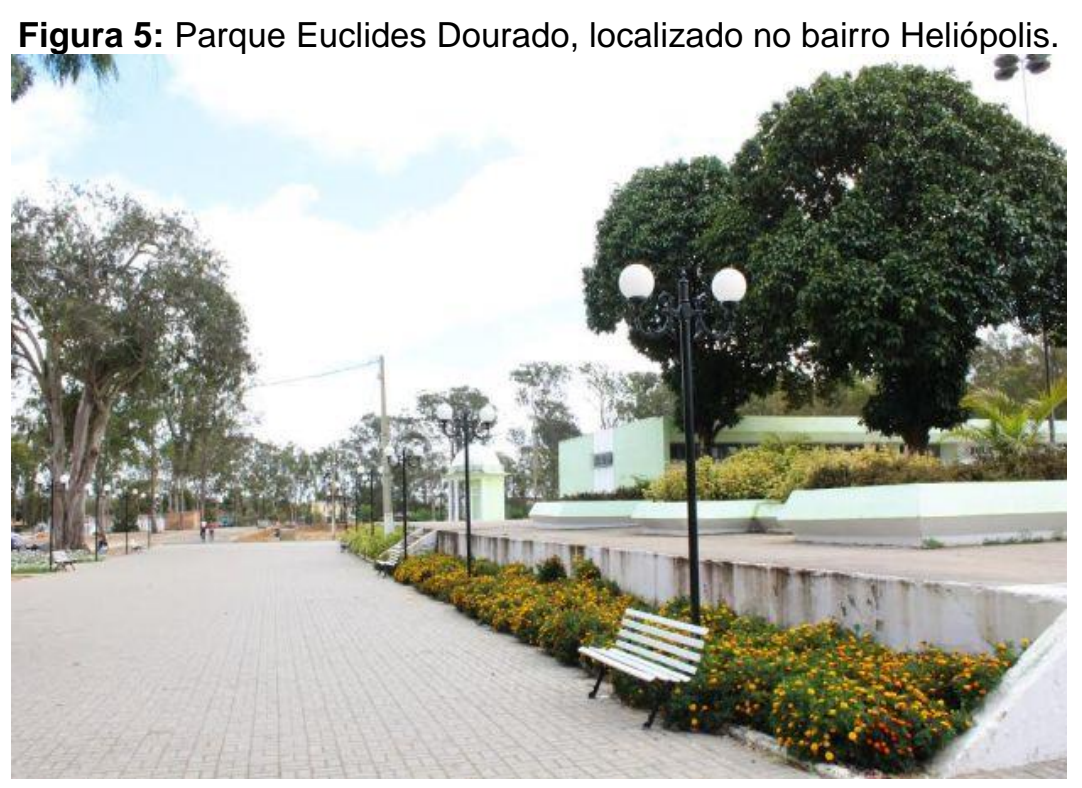

Fonte: TEODORICO \& PORTO, 2015.

\section{Praças}

As praças de Garanhuns são espaços livres de lazer, contemplação, de descanso e de festa. Algumas desempenham mais de uma função, como a praça Cultural Mestre Dominguinhos. Ao total foram observadas 13 praças e a maioria está localizada nos bairro de Santo Antônio e da Boa Vista, sendo em número de 5 e 4 praças, respectivamente. A praça mais conhecida é a popular praça do Relógio das Flores (figura 6), que fica no bairro de Heliópolis. Esta é uma praça de descanso e contemplação. 


\section{Largos}

Existem três largos na cidade de Garanhuns. Neles ocorrem manifestações culturais, em especial no período de inverno, dando lugar aos famosos festivais. Localizam-se no bairro de Santo Antônio. O Espaço Cultural Colunata é uma extensão dos canteiros centrais e do pátio em frente à igreja de Santo Antônio, nele além das apresentações durante os festivais, também ocorrem apresentações de corais na época natalina.

\section{Quadra polivalente}

No levantamento realizado, foi identificada apenas uma quadra que está localizada no bairro da Boa Vista. Apesar de existirem outras quadras polivalentes em Garanhuns, estas são de uso privado e não espaços livres públicos, que é o foco do trabalho.

\section{CONCLUSÃO}

Os espaços livres públicos de Garanhuns, em sua maioria, são do tipo praça. Localizam-se, em grande parte, no bairro de Santo Antônio, que é o bairro central do município e no bairro da Boa Vista. Apenas esses dois bairros somam um total de 9 praças. Também foi verificado que alguns espaços livres públicos exercem mais de uma função como a Praça Cultural Mestre Dominguinhos e o Espaço Cultural Colunata, que em determinadas épocas do ano exerce função de Largo. Há ainda uma extensão do pátio em frente à Catedral de Santo Antônio, que além desta função também é considerada uma praça, com seu canteiros.

Com a delimitação proposta e o objetivo do trabalho cumprido, foi possível verificar a importância da realização de um trabalho desta natureza, ficando a possibilidade de realização de trabalhos futuros que venham a dar conta de um levantamento que contemple todo o território do município, além da real disponibilidade e distribuição desse tipo de espaço livre. 
Assim, a partir dos resultados obtidos com a identificação e o mapeamento dos espaços livres públicos na área urbana central de Garanhuns, verificou-se que no município existem as duas categorias desses espaços, apesar de não se distribuírem de forma equilibrada em seu território, privilegiando os bairros mais centrais, o que permite afirmar que estes não cumprem com uma das principais funções a que se destinam, que é a sociabilidade entre as pessoas do lugar.

\section{REFERÊNCIA}

ALMEIDA, Maria Cecília Fernandes de. Espaços públicos em João Pessoa (1889-1940) Formas, Usos e Nomes. Tese de Mestrado em Arquitetura e Urbanismo. Escola de Engenharia de São Carlos da Universidade de São Carlos, São Carlos, 2006.

BRASIL. Ministério do Planejamento, Orçamento e Gestão. IBGE - Sinopse do Censo Demográfico 2010 Pernambuco. Disponível em

http://www.censo2010.ibge.gov.br/sinopse/index.php?uf=26\&dados=P21, acessado em 23 de janeiro de 2015.

BRASIL. Universidade Federal Rural De Pernambuco. UFRPE Unidade Acadêmica de Garanhuns. Disponível em http://www.ufrpe.br/noticia_ver.php?idConteudo=14436. Acessado em 11 de fevereiro de 2015.

CUNHA, Rita Dione Araújo. Os usos, funções e tratamentos das áreas de lazer da área central de Florianópolis. Tese de Doutorado em Engenharia de Produção. Universidade Federal de Santa Catarina, Florianópolis, 2002.

DOURADO, Catarina de Souza. Parque dos Caldeirões. A educação pela pedra. Trabalho de graduação em Arquitetura e Urbanismo, Universidade Federal de Pernambuco, 2003.

LEITÃO, Lúcia. As praças que a gente quer. Manual de procedimentos para intervenção em praças. Recife: Secretaria de Planejamento Urbano e Meio Ambiente, 2002.

OLIVEIRA, Amannda. Blog falando francamente, 2013. Disponível em http://www.blogfalandofrancamente.com/2013/10/cemiterios-de-garanhuns-sao-preparados.html. Acessado em 11 de fevereiro de 2015.

SÁ CARNEIRO, Ana Rita; MESQUITA, Liana. Espaços Livres do Recife. Recife: Ed. PCR/UFPE, 2000. p26-29.

SILVA, Jessyca. Espaço livre público: Análise do projeto academia da cidade no município de Aliança-PE. Trabalho de conclusão de curso em arquitetura e urbanismo. Faculdade Damas de Recife, 2010.

TEODORICO, Clovis; PORTO, Luanny. Prefeitura de Garanhuns. Disponível em http://www.garanhuns.pe.gov.br/. Acessado em 02 junho de 2015. 